\title{
CUSTOMER NEEDS SIMULATION SYSTEM FOR INVESTIGATING MUST-BE ATTRIBUTE
}

\author{
Md Mamunur Rashid* \\ Bangladesh Institute of Management, 4 Sobhanbag, Mirpur Road, Dhaka-1207, Bangladesh \\ *Corresponding e-mail: mamun87245@gmail.com
}

\begin{abstract}
All the key features, functions, characteristics, and spirit of a design are needed for a full concept for a product. Moreover, every product serves a certain purpose; if a product can't serve its purpose, then it's useless. This is the basis of design, though it can hardly be evaluated and coped with properly. This type attribute is called must-be attribute. Thus, Many trouble occur if Must design is ignored; consequently design cannot provide a design warranty. Thus, computational tools are needed to assist a product development team to determine beforehand the critical number of respondents to make a right decision. In this regard, absolutely this paper presents a Kano model based customer needs simulation system for investigating must-be attribute.
\end{abstract}

Keywords: Product Development, Kano Model, Monte Carlo Simulation, Imprecise Probability, Fuzzy Logic.

\section{INTRODUCTION}

Product development is a complex engineering task wherein a great deal of intellectual and physical resources, methods, tools, and processes are involved to tackle the technical and business issues in an integrated manner so that the targeted group of customers can be satisfied ${ }^{1,4,13}$. Figure 1 shows a simplified view of product development cycle that consists of Strategic Goal, Customer Needs Assessment, Product Conceptualization, Product Realization, and Satisfaction.

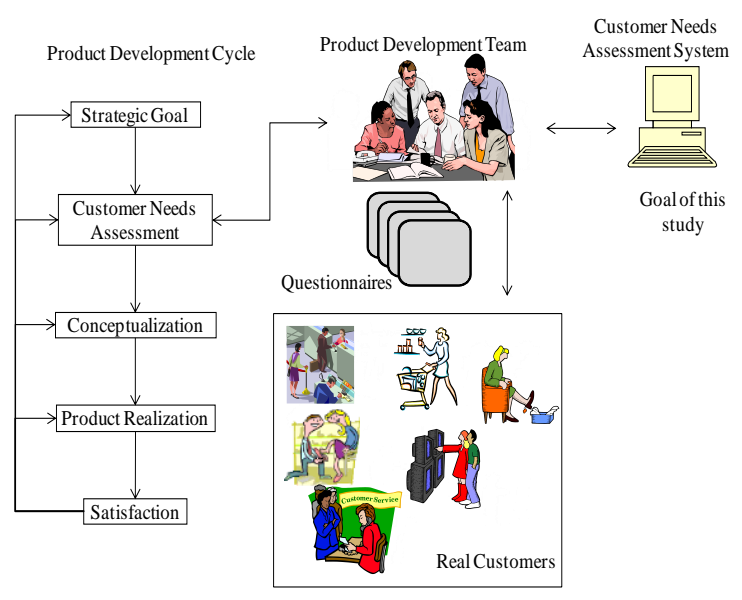

Figure 1. The context of this study.

As seen from Fig. 1, all technical issues of Product Conceptualization and Product Realization are handled after assessing the customer needs. Therefore, the success of a product development process (i.e., desired customer satisfaction) is sensitive to the customer needs assessment process. In most cases, customer needs of a product (or a product family) are incorporated by setting the customer requirements and their relative importance in the first house of quality of $\mathrm{QFD}^{7,8,12}$. This process is somewhat $a d h o c$ and does not provide a clear link between customer satisfaction and product attribute $^{7,12}$. In this regard, Kano Model $^{9}$ is a better choice. A great deal of research has been carried out to get benefitted from Kano Model while setting the customer needs with respect to customer satisfaction $^{2,3,5,10,11,22}$. Yadav and $\operatorname{Singh}^{27}$ have drawn an attention for creating convergent environments from dynamic nature of market and globalization for product development process. Non-conformities (NC) must be removed for product development ${ }^{21}$ for creating convergent dynamic market. Roy et al. ${ }^{20}$ was applied one dimensional questionnaire for user centric design by using Kansei Engineering is shown in Fig.2. In this perspective, Kano model and two dimensional questionnaire regarding Kano model can help to remove Non-conformities (NC) of the product and control the dynamic nature of market, i.e. people, customers, users than one dimensional questionnaire of Kansei is also shown in Fig 2.

As seen from Fig.2, one dimensional questionnaire is shown both satisfaction and dissatisfaction on the same questionnaires, which cannot reduce Non-conformities (NC), because depth of understanding with customer is little present, where two dimensional questionnaire, satisfaction is shown in functional question, other side dissatisfaction is shown in dysfunctional question, which can create conformities in the market, due to depth understanding with customer. Therefore, both functional and dysfunctional questionnaires (two dimensional) are applied to identify product attribute, namely, Attractive, Must-be, One-dimensional, Indifferent, and Reverse. i.e. Kano evaluation for compliance customer needs with product development. An attribute is considered a Must-be attribute, if its absence produces absolute dissatisfaction and its presence does not increase the satisfaction. For this purpose, Must-be attribute is needed to study. Yet, researchers could not study regarding must-be attribute. Although they are active in this field ${ }^{13-19}$. For this purpose, the system development is studied in the following section. Then next describes a case study about the must-be attribute. Last section concludes. 
One-dimensional Questionnaire:

The bicycle has circle-shaped wheels. Are your satisfied?

$\square$ Satisfied

을 Somewhat Satisfied

$\square$ Less Satisfied

$\square$ Not Satisfied

$\square$ NotSure

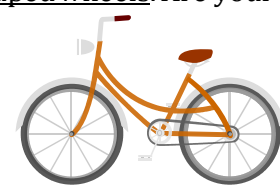

Two-dimensional Questionnaire:

Functional Question:

Dysfunctional Question:

The bicycle has circle-shaped wheels? The bicycle does not have circle-shaped wheels?
$\square$ Like
$\square$ Must-be
$\square$ Neutral
$\square$ Live-with
$\square$ Dislike

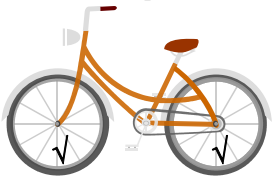
$\square$ Like
$\square$ Must-be
ㅁ Neutral
$\square$ Live-with
$\square$ Dislike

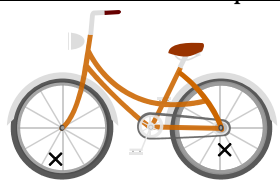

Figure 2. Examples of typical questionnaires.

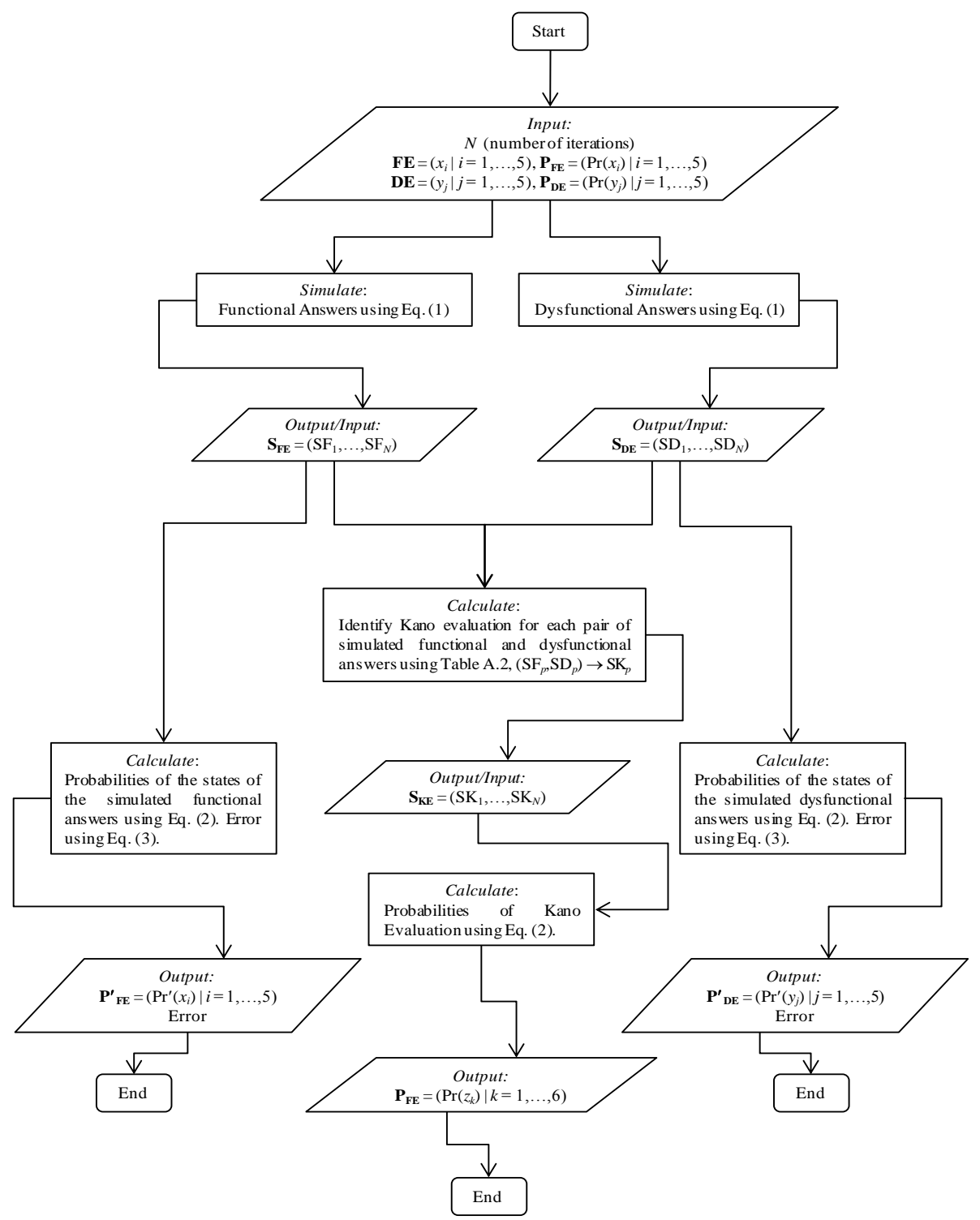

Figure 3. Outline of the proposed system.

Journal of Mechanical Engineering, Vol. ME 44, No. 1, June 2014

Transaction of the Mechanical Engineering Division, The Institution of Engineers, Bangladesh 


\section{SYSTEMS DEVELOPMENT}

This section describes the system development for simulating functional/dysfunctional answers in accordance with Kano Model. The simulation procedure described in the previous section is used to develop the system. First the layout of the system is described as follows:

Consider that $\mathbf{F E}=$ (Like, Must-be, Neutral, Live-with, Dislike) is a vector that contains all possible states of functional answers. For convenience, $x_{i}$ will be used to denote $i$-th element of $\mathbf{F E}, i=1, \ldots, 5$. $\mathbf{P}_{\mathrm{FE}}=\left(\operatorname{Pr}\left(x_{i}\right) \mid i=1, \ldots, 5\right)$ is the probability vector of the states of functional answers defined by $\mathbf{F E}$. The corresponding cumulative probability vector is denoted by $\mathbf{C P}_{\mathrm{FE}}=\left(\operatorname{CPr}\left(x_{i}\right) \mid i=1, \ldots, 5\right)$. In addition, consider that $\mathbf{D E}=($ Like, Must-be, Neutral, Live-with, Dislike) is a vector that contains all possible states of dysfunctional answers. For convenience, $y_{j}$ will be used to denote $j$-th element of $\mathbf{D E}, j=1, \ldots, 5 . \mathbf{P}_{\mathbf{D E}}=\left(\operatorname{Pr}\left(y_{j}\right) j=1, \ldots, 5\right)$ is the probability vector of the states of dysfunctional answers defined by DE. The corresponding cumulative probability vector is denoted by $\mathbf{C P}_{\mathbf{D E}}=\left(\operatorname{CPr}\left(y_{j}\right) \mid j=1, \ldots, 5\right)$. Moreover, consider that $\mathbf{K E}=($ Attractive, One-dimensional, Must-be, Indifferent, Reverse, Questionable) is a vector that contains all possible states of Kano evaluations. For convenience, $z_{k}$ will be used to denote $k$-th element of $\mathbf{K E}, k=1, \ldots, 6 . \mathbf{P}_{\mathbf{K E}}=\left(\operatorname{Pr}\left(z_{k}\right) \mid k=1, \ldots, 6\right)$ is the probability vector of the states of Kano evaluation defined by $\mathbf{K E}$. A combination of functional and dysfunctional answers $\left(x_{i}, y_{j}\right)$ corresponds to a definite Kano evaluation $z_{k}$, i.e., $\left(x_{i}, y_{j}\right) \rightarrow z_{k}$, in accordance with the Kano model. See Table A.2 for all possible mapping $\left(x_{i}, y_{j}\right) \rightarrow z_{k}$. However, to simulate functional answer $x_{i}$ and dysfunctional answer $y_{j}$, independently, and, thereby, the Kano Evaluation $z_{k}$, a simulation process is proposed as illustrated in Fig. 3. The proposed process composed of five steps (Step $0, \ldots$, Step 4 ). The steps are explained as follows:

Step 0: This step is to input number of iterations $(N)$, event and probability vectors of functional and dysfunctional answer $\quad\left(\mathbf{F E}=\left(x_{i} \mid i=1, \ldots, 5\right)\right.$, $\mathbf{P}_{\mathbf{F E}}=\left(\operatorname{Pr}\left(x_{i}\right) \mid i=1, \ldots, 5\right), \quad \mathbf{D E}=\left(y_{j} \mid j=1, \ldots, 5\right), \quad$ and $\left.\mathbf{P}_{\mathrm{DE}}=\left(\operatorname{Pr}\left(y_{j}\right) j=1, \ldots, 5\right)\right)$.

Step 1: This step is to simulate and display the functional and dysfunctional answers independently using the process .Tr lts are two ve of simulated functional and dysfunctional answers $\mathbf{S}_{\mathrm{FE}}=\left(\mathrm{SF}_{1}, \ldots, \mathrm{SF}_{N}\right) \quad$ and $\quad \mathbf{S}_{\mathrm{DE}}=\left(\mathrm{SD}_{1}, \ldots, \mathrm{SD}_{N}\right)$, respectively. As such, $\mathrm{SF}_{p}=x_{i}$ and $\mathrm{SD}_{p}=y_{j}, p=1, \ldots, N$, $\exists i, j \in\{1, \ldots, 5\}$.

Step 2: This step is to calculate and display the probability vectors of simulated functional and dysfunctional answers $\left(\mathbf{P}_{\mathrm{FE}}^{\prime}=\left(\operatorname{Pr}^{\prime}\left(x_{i}\right) \mid i=1, \ldots, 5\right)\right.$ and $\left.\mathbf{P}^{\prime}{ }_{\mathbf{D E}}=\left(\operatorname{Pr}^{\prime}\left(y_{j}\right) \mid j=1, \ldots, 5\right)\right)$ and corresponding Error using the processes .
Step 3: This step is to use $\mathbf{S}_{\mathbf{F E}}=\left(\mathrm{SF}_{1}, \ldots, \mathrm{SF}_{N}\right)$ and $\mathbf{S}_{\mathrm{DE}}=\left(\mathrm{SD}_{1}, \ldots, \mathrm{SD}_{N}\right)$ and identify the Kano Evaluation for each pair of simulated functional and dysfunctional answers using the definition $\left(x_{i}, y_{j}\right) \rightarrow z_{k}$ shown in Table A.2. This step thus produces a vector of simulated Kano Evaluations $\mathbf{S}_{\mathbf{K E}}=\left(\mathrm{SK}_{1}, \ldots, \mathrm{SK}_{N}\right)$ so that $\left(\mathrm{SF}_{p}, \mathrm{SD}_{p}\right) \rightarrow \mathrm{SK}_{p}=z_{k}, p=1, \ldots, N, \exists k \in\{1, \ldots, 6\}$.

Step 4: This step is to determine the probability vector of the simulated Kano Evaluations $\mathbf{P}_{\mathbf{F E}}=\left(\operatorname{Pr}\left(z_{k}\right) \mid k=1, \ldots, 6\right)$ using the process .

Based on the outline of the system, shown in Fig. 3 and described by Step $0, \ldots$, Step 4 , a system is developed that runs on Microsoft Excel ${ }^{\circledR}$ environment. Figure 6 shows the screen-short of a part of the user-interface of the developed system, wherein three input items (Number of Virtual Customers (i.e., number of iterations $N$ ), probabilities of the states of functional answers, and probabilities of the states of dysfunctional answers) are shown. In addition, one of the outputs (Kano Evaluations) is also shown in Fig. 4. The errors are not shown. The variation in the Kano Evaluation for ten different independent simulations (each simulation consists of 100 iterations, as shown in Fig. 4 is also displayed in the bar chart of Kano Evolution in Fig. 4.

\section{A CASE STUDY}

Consider the case shown in Fig. 5. As seen from Fig. 5 , there is a questionnaire regarding a product (bicycle) attribute (circle-shaped wheel). It is well-known that circular wheel of a bicycle is a "Must-be" (in Japanese "Atarimae") attribute. Therefore, the ideal answer of a respondent would be "must-be" from functional side (i.e., the bicycle should have circular wheel) and "dislike" from dysfunctional side (i.e., other shapes of wheel it is not at all desirable). This combination of answer (must-be, dislike) yields a "Must-be" attribute according to Kano Evaluation (see Table A. 2).

In reality, respondents exhibit a rather fuzzy behavior and sometimes answer different than the ideal one. For example, see the frequency of the answers of 27 respondents shown in Fig. 5 obtained during this study. Some respondents answer makes the attribute Must-be, some others answers make it "Attractive," and so on. This raises a fundamental question that is how many respondents should be asked to know for sure that the given attribute is a Must-be attribute.

This question can be answered using the system shown in the previous section. To use the system shown in the previous section, the first step is to input the probability vectors of functional answers and dysfunctional answers. To determine the probability vectors of functional/dysfunctional answers the following procedure can be used.

As it is seen from the case shown in Fig. 5, from the functional side, the respondents are "most-likely" to choose Must-be, "some-likely" to choose "Like" and "less-likely" to choose Neutral, Live-with, or Dislike. 


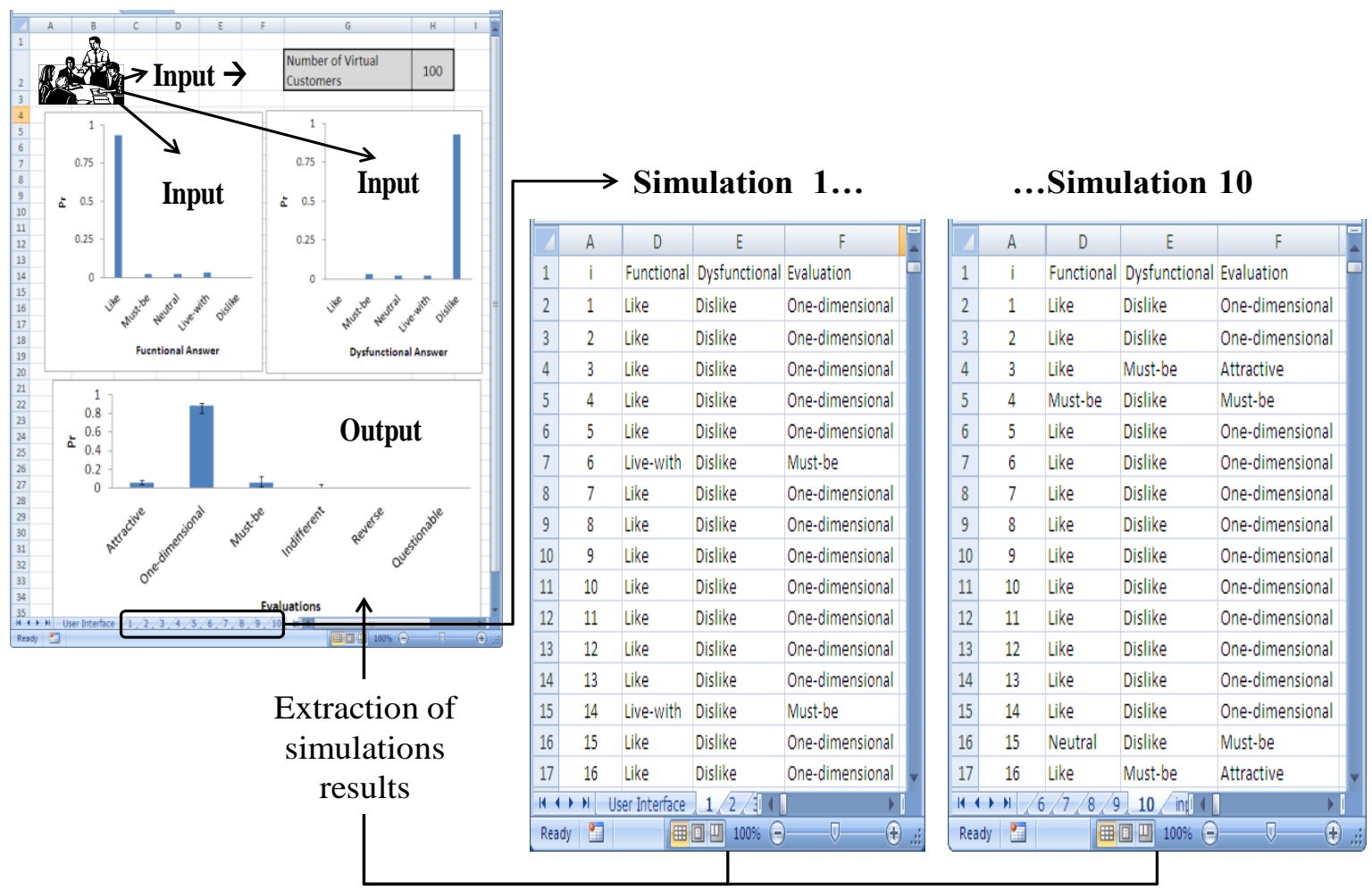

Figure 4. Screen-print of a part of user-interface of the system developed.
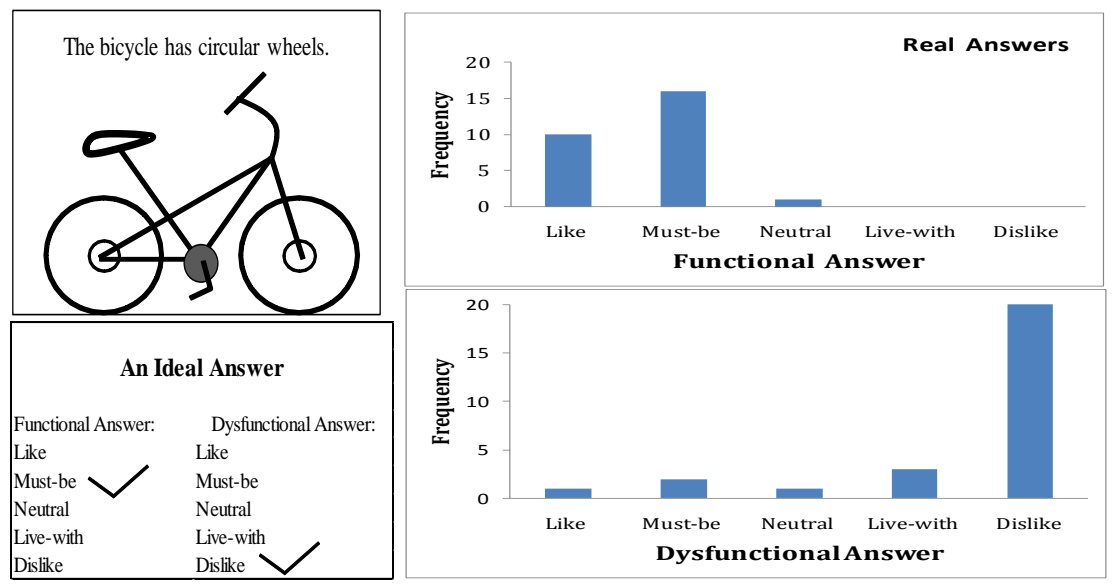

Figure 5. Ambiguity in respondents' answers.

On the other hand, from the dysfunctional side, the respondents are "most-likely" to choose Dislike, "some-likely" to choose Live-with, and "less-likely" to choose Neutral, Must-be, or Like. These linguistic likelihoods ("most-likely", "some-likely", "lesslikely", and so on) can be converted into numeri- cal (crisp) probability using the fuzzy logic. Ullah and Tamaki $^{23}$ and Ullah and $\mathrm{Harib}^{25}$ have provided a fuzzy-logic-based method. The authors used this method here. Figure 6 illustrates the fuzzy numbers defining such linguistic likelihoods as "most-likely," "quite-likely," "some-likely," and "less-likely." The membership functions denoted by $\mu:[0,1] \rightarrow[0,1]$ of these linguistic likelihoods are defined in Appendix B.

From the linguistic likelihoods shown in Fig. 6, the average value and lower and upper limits of are determined using centroid method and $\alpha$-cuts at $\alpha=0.5$, respectively. See the reference (Ullah and Harib ${ }^{25}$ ) for more details. The results are shown in Table 1.

Table 2 shows the probabilities of functional answers for average and worst-case scenarios. For average scenario the average probabilities of linguistic likelihoods (shown in Table 1) are used. These probabilities are normalized to calculate crisp 
probabilities shown in 4-th column in Table 2. For worst-case scenario, the lower limit of most-likely is used and upper limits of some-likely and less-likely are used. These limits are normalized to calculate the crisp probabilities for worst-case scenarios, as shown in last column in Table 2.

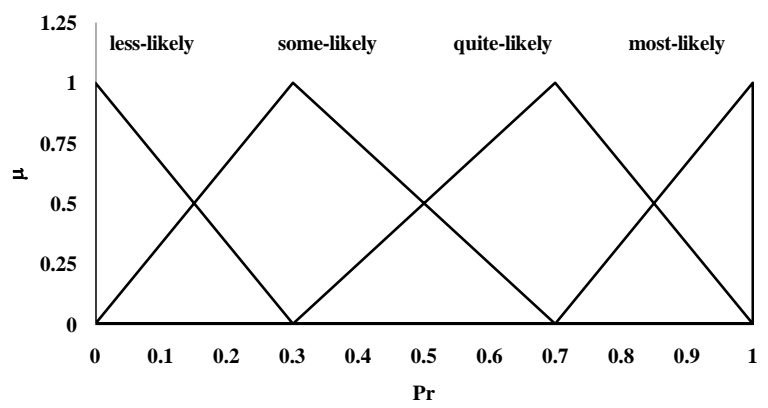

Figure 6. Defining linguistic likelihoods by fuzzy numbers (adapted from Ullah \& Tamaki ${ }^{23}$ ).

Table 1. Numerical probability of linguistic likelihoods.

\begin{tabular}{c|l|l|l}
\hline \hline \multirow{2}{*}{$\begin{array}{l}\text { Linguistic } \\
\text { likelihoods }\end{array}$} & \multicolumn{3}{|l}{ Pr } \\
\cline { 2 - 4 } & $\begin{array}{l}\text { Lower } \\
\text { limit }\end{array}$ & $\begin{array}{l}\text { Upper } \\
\text { limit }\end{array}$ & Average \\
\hline most-likely & 0.85 & 1 & 0.9 \\
quite-likely & 0.5 & 0.85 & $2 / 3$ \\
some-likely & 0.15 & 0.5 & $1 / 3$ \\
less-likely & 0 & 0.15 & 0.1 \\
\hline \hline
\end{tabular}

Table 2. Probabilities of functional answers for average and worst-case scenarios.

\begin{tabular}{r|l|l|l|l|l}
\hline \multicolumn{2}{c|}{} & \multicolumn{2}{l}{ average scenario } & \multicolumn{2}{l}{ worst-case scenario } \\
\hline $\begin{array}{r}\text { Functional } \\
\text { Answers }\end{array}$ & $\begin{array}{l}\text { Linguisti } \\
\text { c } \\
\text { likelihoo } \\
\text { ds }\end{array}$ & $\begin{array}{l}\text { aver } \\
\text { age } \\
\text { Pr }\end{array}$ & Crisp Pr & $\begin{array}{l}\text { upper/l } \\
\text { ower } \\
\text { limits } \\
\text { of Pr }\end{array}$ & Crisp Pr \\
\hline Like & some-likely & $1 / 3$ & $\begin{array}{l}0.2173913 \\
04\end{array}$ & 0.5 & 0.277777778 \\
Must-be & most-likely & 0.9 & $\begin{array}{l}0.5869565 \\
22\end{array}$ & 0.85 & 0.472222222 \\
Neutral & less-likely & 0.1 & $\begin{array}{l}0.0652173 \\
91\end{array}$ & 0.15 & 0.083333333 \\
Live-with & less-likely & 0.1 & $\begin{array}{l}0.0652173 \\
91\end{array}$ & 0.15 & 0.083333333 \\
Dislike & less-likely & 0.1 & $\begin{array}{l}0.0652173 \\
91\end{array}$ & 0.15 & 0.083333333 \\
\hline \hline
\end{tabular}

Similarly the probabilities of dysfunctional answers for average and worst-case scenarios are determined and listed in Table 3. The results shown in Tables 2-3 provide two sets of probabilities for simulating functional/dysfunctional answers. These probabilities are illustrated in Fig.7. Using these probabilities a study has been carried out to determine the minimum number of respondents to conclude that whether or not an attribute is Must-be attribute or else. Figure 8 shows the results for average scenario. As seen from Fig. 8, for 20 respondents there is overlaps among the probabilities of Must-be, Attractive, and Indifferent. This means that using the results of 20 respondents it is not possible to conclude that the attribute is a Must-be attribute. For the case of 50 respondents, still there is an overlap between the probabilities of Must-be and Indifferent. On the other hand, when 100 respondents are used, the overlap disappears and the trend remains more or less the same even if more respondents are used (e.g., compare the results of 100 respondents and 200 respondents shown in Fig. 9).

Table 3. Probabilities of dysfunctional answers for average and worst-case scenarios.

\begin{tabular}{r|r|l|l|l|l}
\hline \multicolumn{2}{l|}{} & \multicolumn{2}{|l|}{ average scenario } & \multicolumn{2}{l}{ worst-case scenario } \\
\hline $\begin{array}{l}\text { Dysfunction } \\
\text { al } \\
\text { Answers }\end{array}$ & $\begin{array}{l}\text { Linguistic } \\
\text { likelihoods }\end{array}$ & $\begin{array}{l}\text { aver } \\
\text { age } \\
\text { Pr }\end{array}$ & $\begin{array}{l}\text { Crisp } \\
\text { Pr }\end{array}$ & $\begin{array}{l}\text { upper/ } \\
\text { lower } \\
\text { limits } \\
\text { of Pr }\end{array}$ & Crisp Pr \\
\hline Like & less-likely & 0.1 & $\begin{array}{l}0.0652 \\
17391\end{array}$ & 0.15 & 0.083333333 \\
Must-be & less-likely & 0.1 & $\begin{array}{l}0.0652 \\
17391\end{array}$ & 0.15 & 0.083333333 \\
Neutral & less-likely & 0.1 & $\begin{array}{l}0.0652 \\
17391\end{array}$ & 0.15 & 0.083333333 \\
Live-with & some-likely & $1 / 3$ & 0.2173 & 0.5 & 0.277777778 \\
Dislike & most-likely & 0.9 & $\begin{array}{l}91304 \\
56522\end{array}$ & 0.85 & 0.472222222 \\
\hline \hline
\end{tabular}
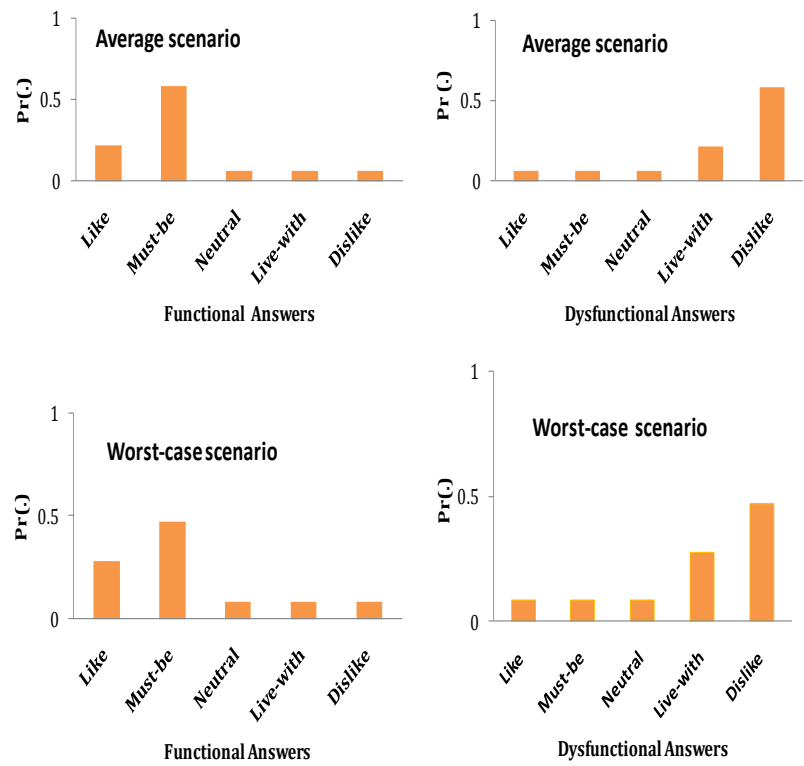

Figure 7. Probabilities of functional/dysfunctional answers for two scenarios.

Therefore, at least answers from 100 respondents should be collected to determine that an attribute is a Must-be attribute. What if the other set of probabilities (probabilities for worst-case scenario) is used? Figure 9 shows the results for this case. As seen from Fig. 9, even though a large number of respondents are used, an overlap between the probabilities of Must-be and Indifferent remains. 


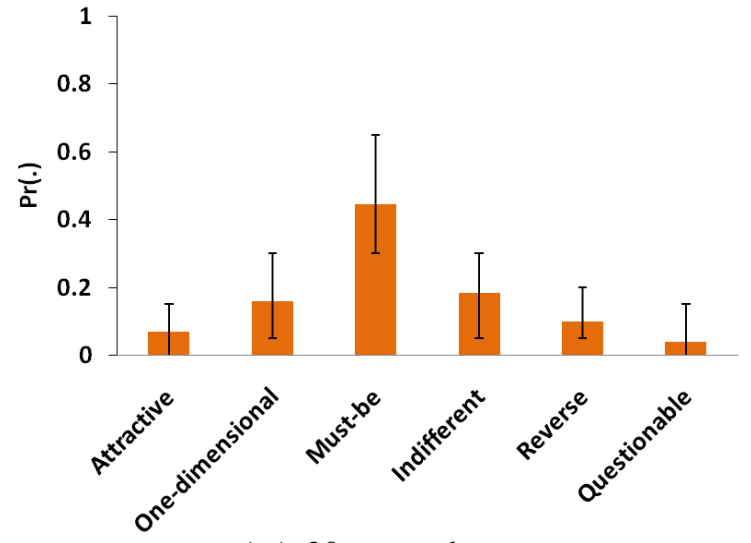

(A) 20 respondents

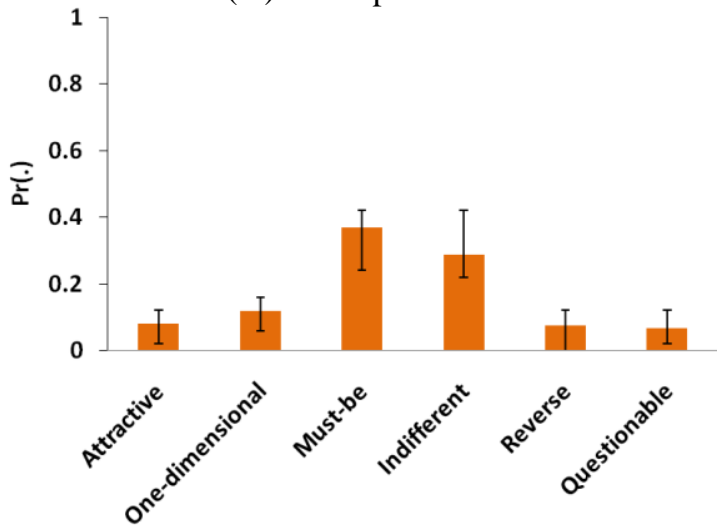

(B) 50 respondents

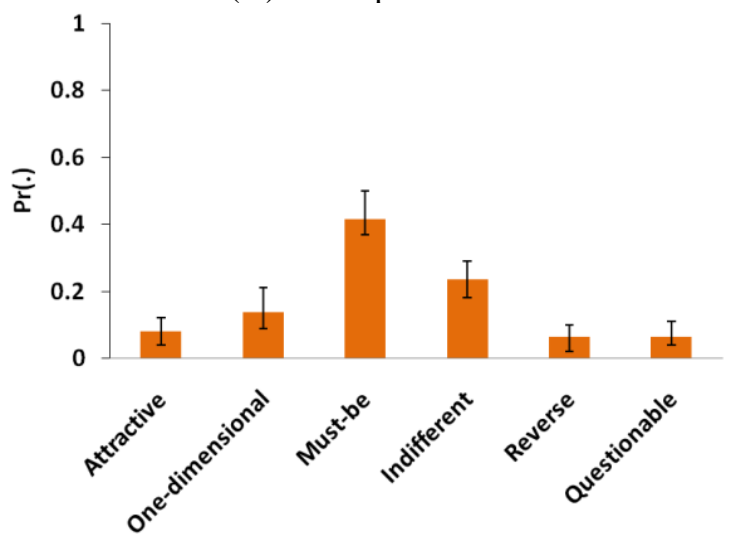

(c) 100 respondents

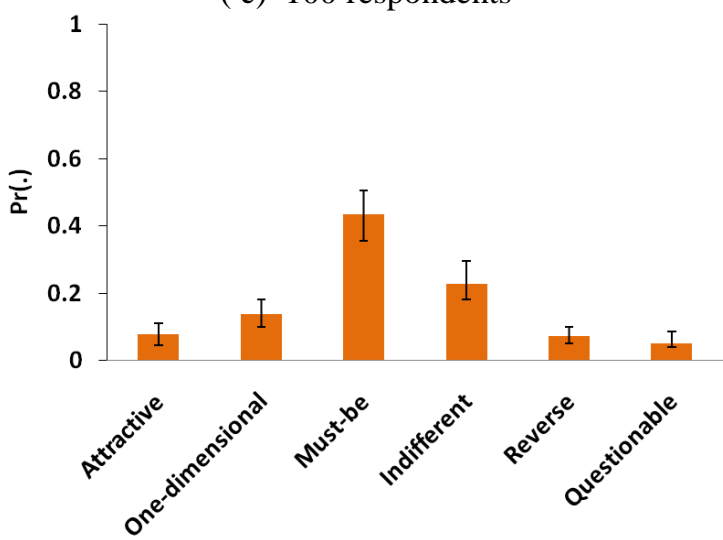

(D) 200 respondents

Figure 8. Number of respondents versus Kano Evaluation for average scenario.

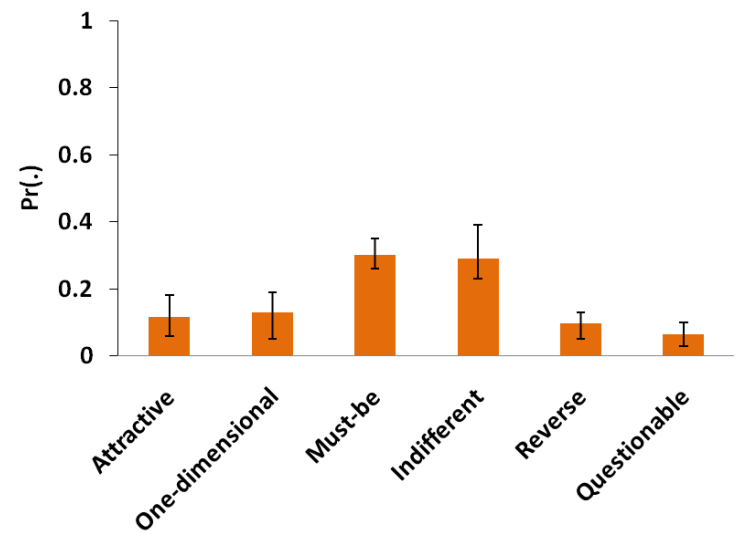

(a) 100 respondents

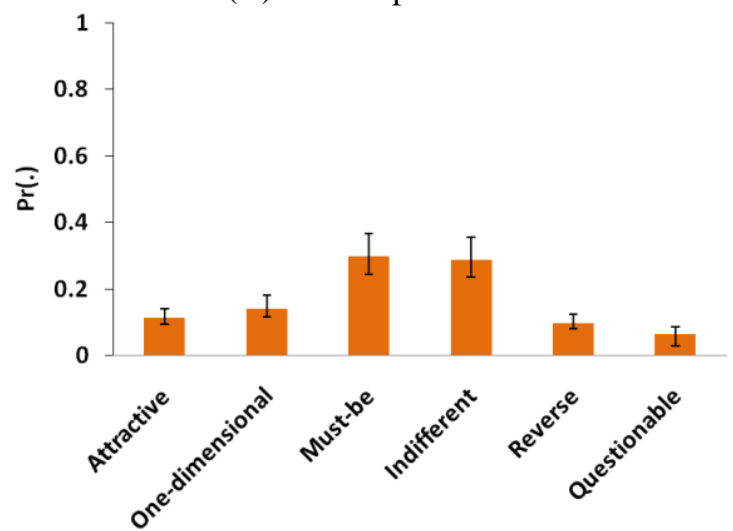

( b) 200 respondents

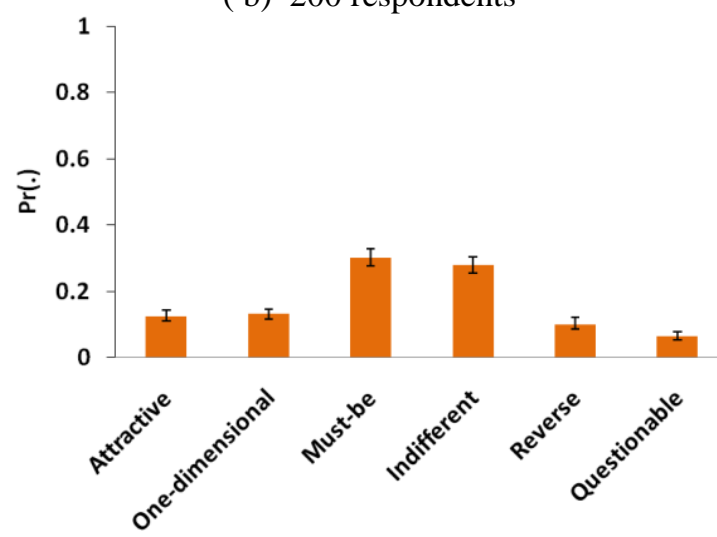

c) 1000 respondents

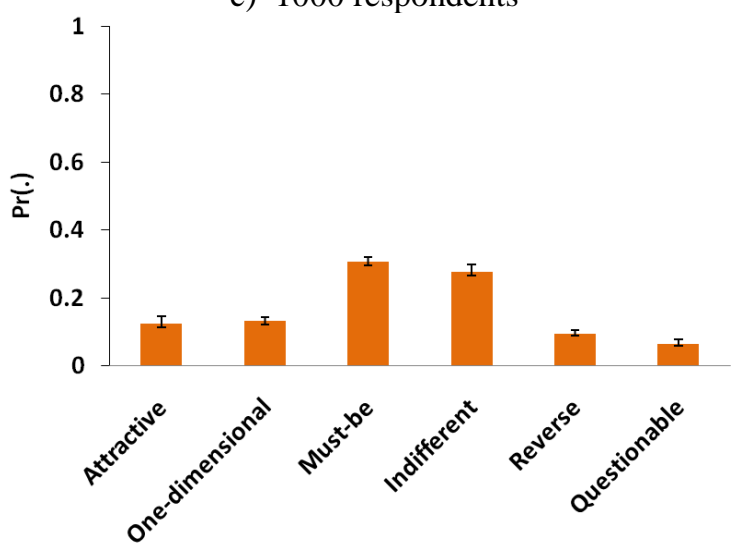

(d) 2000 respondents

Figure 9. Number of respondents versus Kano Evaluations for worst-case. 
This means that if the there is tie between Must-be and Indifferent, the attribute should be considered a Must-be attribute. Otherwise, the probability of Indifferent should have been much higher than that of Must-be.

Based on the above results it can be concluded that if the answers of at least 100 respondents show a tie between must-be and Indifferent (worst-case scenario) or probability of Must-be is greater than that of others, then the attribute should be considered a Must-be attribute. This working principle can be used as a guideline while distinguishing a Must-be attribute from others in all kinds of product. Similar study can be carried out for other types of attributes.

Moreover, the presented system can be used to simulate customer answers wherein the customers are taken from different demographic and/or psychographic background factors of the respondents of known and unknown answers are similar. This issue remains open for further study.

In Kano model, a questionnaire is a two-dimensional one wherein a combination of two answers determines the level of satisfaction. Sometimes, one-dimensional questionnaire are used to know the level of satisfaction (see for example the questionnaire in Roy et al. ${ }^{20}$ ).

\section{CONCLUDING REMARKS}

The presented customer needs assessment system can assist a product development team by providing an answer to the question: at least how many respondents should be asked to determine whether or not an attribute is Must-be, Attractive, One-dimensional, Indifferent, or Reverse attribute in accordance with Kano Model. In particular, it is found that at least 100 respondents should be asked to determine whether or not an attribute is a Must-be attribute. The system can be customized for other customer needs assessment model that uses one-dimensional questionnaire or multi-dimensional questionnaire.

\section{REFERENCES}

1. Browning, T.R., Fricke, E. \& Negele, H. (2006), Key concepts in modeling product development processes, Systems Engineering, 9(2), 104-128.

2. Chen, C.C. \& Chuang, M.C. (2008), Integrating the Kano Model into a Robust Design Approach to Enhance Customer Satisfaction with Product Design, International J. of Production Economics, 114(2), 667-681.

3.Chen, H.C., Lee, T.R. Lin, H.Y. \& Wu, H.C. (2010), Application of TRIZ and the Kano Method to Home Life Industry Innovation, International J. of Innovation and Learning, 7(1), 64-84.

4.Fujita, K. \& Matsuo, T. (2006), Survey and analysis of utilization of tools and methods in Product development, Transactions of the Japan Society of Mechanical Engineers, Series C,72(713), 290-297.
5.Fuller, J. \& Matzler, M. (2007), Virtual product experience and customer participation-A chance for customer-centred, really new products, Technovation, 27(6-7), 378-387.

6. Hillier, F.S. \& Lieberman, G.J. (2005). Introduction to Operations Research, New York: McGraw Hill.

7.Hari, A., Kasser, J.E. \& Weiss, M.P. (2007), How Lessons Learned from Using QFD Led to the Evolution of a Process for Creating Quality Requirements for Complex Systems, Systems Engineering, 10(1), 45-63.

8.Kobayashi, H. (2006), A systematic approach to eco-innovative product design based on life Cycle planning, Advanced Engineering Informatics, 20(2), 113-125.

9. Kano, N.,Seraku, N.(1984), Takahashi, F. and Tsuji, S., Attractive quality and must-be quality, Hinshitsu, 14(2),39-48.

10. Lee, Y.C. \& Huang, S.Y. (2009), A New Fuzzy Concept Approach for a New Fuzzy Concept on Kano's Model, Expert Systems with Applications, 36(3), 4479-4484.

11.Matzler, K. \& Hinterhuber, H.H. (1998), How to make product development projects more successful by integrating Kano's model of customer satisfaction into quality function deployment, Technovation, 18(1), 25-38.

12. Poel, I.V.d. (2007), Methodological problems in QFD and directions for future development, Research in Engineering Design, 18(1), 21-36.

13.Rashid, M.M., Tamaki, J., Ullah, A.M.M.S. \& Kubo, A., (2010), A Virtual Customer Needs System for Product Development, Proceedings of the JSPE Hokkaido Chapter Annual Conference, 2010, Japan.

14. Rashid M. M. (2010), A Simulating functional and dysfunctional answer from given Kano evaluation for Product Development, Proceedings of $1^{\text {st }}$ International Conference on Mechanical,Industrial and Energy Engineering, Khulna, Bangladesh,1-6.

15. Rashid M. M., Ullah A.M.M.S., Tamaki J. and Kubo A. (2010), A Numerical Method for Customer Need Analysis, Proceedings of the 13 Annual Paper Meeting Conference on Mechanical Engineering APM, IEB, Bangladesh, 1-6.

16. Rashid M. M. (2010), A review of state-of -Art on Kano Model for Research Direction, International J. of Engineering, Science and Technology, 2(12),74817490 .

17. Rashid M. M., Ullah A.M.M.S., Tamaki J. and Kubo A. (2010). A Kano Model based Computer System for Respondents determination: Customer Needs Analysis for Product development Aspects, Management Science and Engineering, 4 (4), 70-74.

18. Rashid M. M., Ullah A.M.M.S., Tamaki J. and Kubo A. (2010), A proposed computer system on Kano Model for new product development and innovation aspect: A case study is conducted by an attractive 
attribute of automobile, International J. of Engineering, Science \& Technology, 2(9),1-12. 19. Rashid M. M., Ullah A.M.M.S., Tamaki J. and Kubo A. (2011), A Numerical Kano Model for compliance customer needs with product development. Industrial Engineering and Management Systems, 10 (2), 140-153.

20. Roy, R. Goatman, M. \& Khangura, K. (2009), User-centric design and Kansei Engineering, CIRP Journal of Manufacturing Science and Technology, 1 (3), 172-178.

21.Savino, M.M., Apolloni, S. \& Ouzrout, Y. (2008), Product quality pointers for small lots Production: a new driver for Quality Management System, Int. J. Product Development, 5(1-2), 199-211.

22.Sireli, Y., Kauffmann, P. \& Ozan, E. (2007), Integration of Kano's Model into QFD for Multiple Product Design, IEEE Transactions on Engineering Management, 54(2),380-390.

23.Ullah, A.M.M.S. \& Tamaki, J. (2009), Uncertain Customer Needs Analysis for Product Development: A Kano Model Perspective, Proceedings of the Sixth International Symposium on Environmentally Conscious Design and Inverse Manufacturing, Sapporo, Japan.

24.Ullah, A.M.M.S. \& Tamaki, J. (2010), Analysis of Kano-Model-Based Customer Needs for Product Development, Systems Engineering, 14(2), 154-172.

25.Ullah, A.M.M.S. \& Harib, K.H. (2006), A Human-Assisted Knowledge Extraction Method for Machining Operations, Advanced Engineering Informatics, 20(4), 335- 350.

26.Xu, Q., Jiao, R.J., Yang, X., Helander, M., Khalid, H.M. \& Opperud, A. (2009), An Analytical Kano Model for Customer Need Analysis, Design Studies, 30 (1),87-110.

27. Yadav, O.P. and Singh, N. (2008), Perspectives and challenges for product reliability assurance in the product development process, Int. J. Product development, 5 (1-2), 4-16.

\section{APPENDIX A: Kano Model}

Kano Model defines the relationships between customer satisfaction and product attribute (Fig.A.1) and provides five types of product attributes, namely, Attractive, Must-be, One-dimensional, Indifferent, and Reverse.In Fig.A.1, the upward vertical axis represents satisfaction and downward vertical axis represents dissatisfaction. The leftward horizontal axis represents absence of performance (the attribute is not working/not present) that is called dysfunctional side. The rightward horizontal axis represents presence of performance (the attribute is working/present) that is called functional side.

Table A1 describes the meaning of Must-be (M), One-dimensional $(\mathrm{O})$, Attractive (A), Indifferent (I), and Reverse $(\mathrm{R})$ attribute.

Table A1. Five classes of product attributes used in Kano model.

\begin{tabular}{|c|c|c|}
\hline $\begin{array}{l}\text { Product } \\
\text { attributes }\end{array}$ & Definition & Recommendations \\
\hline Attractive & $\begin{array}{c}\text { An attribute is } \\
\text { considered an Attractive } \\
\text { attribute, if it leads to a } \\
\text { better satisfaction, } \\
\text { whereas it is not } \\
\text { expected to be in the } \\
\text { product. }\end{array}$ & $\begin{array}{c}\text { Include a good } \\
\text { number of Attractive } \\
\text { attributes }\end{array}$ \\
\hline $\begin{array}{c}\text { One } \\
\text {-dimensional }\end{array}$ & $\begin{array}{c}\text { An attribute is } \\
\text { considered a } \\
\text { One-dimensional } \\
\text { attribute, if its } \\
\text { fulfillment helps } \\
\text { enhance the satisfaction } \\
\text { and vice versa. }\end{array}$ & $\begin{array}{l}\text { Include a good } \\
\text { number of } \\
\text { One-dimensional }\end{array}$ \\
\hline Must-be & $\begin{array}{c}\text { An attribute is } \\
\text { considered a Must-be } \\
\text { attribute, if its absence } \\
\text { produces absolute } \\
\text { dissatisfaction and its } \\
\text { presence does not } \\
\text { increase the satisfaction. }\end{array}$ & $\begin{array}{l}\text { Continue Must-be } \\
\text { attributes }\end{array}$ \\
\hline Indifferent & $\begin{array}{c}\text { An attribute is } \\
\text { considered an } \\
\text { Indifferent attribute, that } \\
\text { result neither in } \\
\text { satisfaction nor } \\
\text { dissatisfaction, whether } \\
\text { fulfilled or not. }\end{array}$ & $\begin{array}{c}\text { Avoid Indifferent } \\
\text { attributes as many as } \\
\text { possible }\end{array}$ \\
\hline Reverse & $\begin{array}{c}\text { The attribute that leads } \\
\text { to absolute } \\
\text { dissatisfaction. }\end{array}$ & Should be avoided \\
\hline
\end{tabular}

To know whether or not a given attribute is Attractive, Must-be, One-dimensional, Indifferent, or Reverse, it is important to fill out a two-dimensional questionnaire prepared for each attribute under consideration. One of the dimensions of the questionnaire is called functional answer (i.e., the answer when the attribute is working/present) and the other dimension is called dysfunctional answer (i.e., the answer when the attribute is not working/not present). A respondent needs to answer one state out of 
Like, Must-be, Neutral, Live-with, and Dislike from functional side. The respondent needs to do the same for the dysfunctional side. The combination of answers determines whether the respondent considers the underlying attribute an Attractive, One-dimensional, Must-be, Indifferent, or Reverse attribute. Some combinations of answers do not make sense. This type of answer is called "Questionable" answer. This leads to a mapping called Kano Evaluation as shown in Table A2.
Table A2. Kano Evaluations $\left(z_{k}\right)$

\begin{tabular}{c|l|l|l|l|l}
\hline \hline \multirow{2}{*}{$\begin{array}{c}\text { Functional } \\
\text { Answer }\left(x_{i}\right)\end{array}$} & \multicolumn{5}{|c}{ Dysfunctional Answer $\left(y_{j}\right)$} \\
\cline { 2 - 6 } & Like & Must-be & Neutral & Live-with & Dislike \\
\hline Like & Q & A & A & A & O \\
Must-be & R & I & I & I & M \\
Neutral & R & I & I & I & M \\
Live-with & R & I & I & I & M \\
Dislike & R & R & R & R & Q \\
\hline
\end{tabular}

$\mathrm{A}=$ Attractive, $\mathrm{I}=$ Indifferent, $\mathrm{M}=$ Must-be, $\mathrm{O}=$ One-dimensional, $\mathrm{Q}=\mathrm{Questionable}$, and $\mathrm{R}=$ Reverse

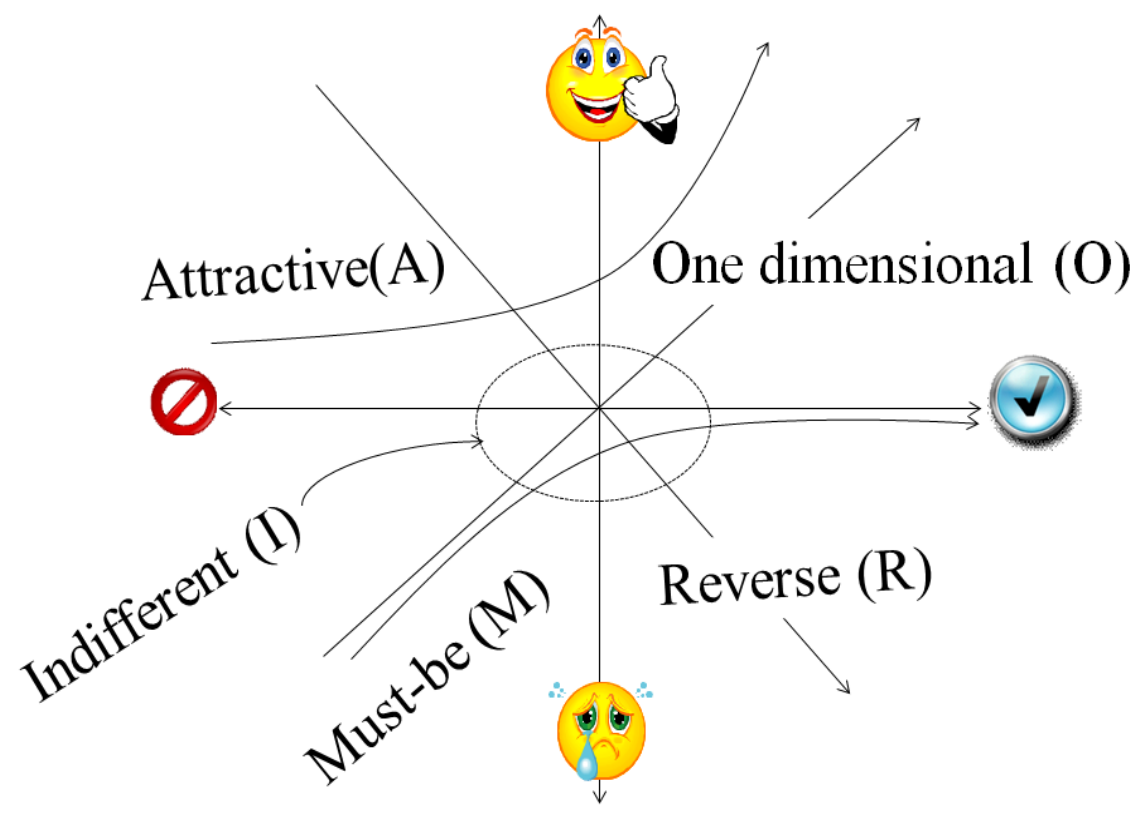

Figure A1. Correlation between product attribute and customer satisfaction in Kano model.

\section{APPENDIX B: Membership Functions of Linguistic Likelihood}

The membership functions $\left(\mu_{(.)}(\operatorname{Pr})\right)$ of the linguistic likelihoods denoted by less-likely, some-likely, quite-likely, and most-likely are given, as follows:

$$
\begin{aligned}
& \mu_{\text {less-likely }}(\operatorname{Pr})=\max \left(0, \min \left(1, \frac{0.3-\mathrm{Pr}}{0.3-0}\right)\right) \\
& \mu_{\text {some-likely }}(\mathrm{Pr})=\max \left(0, \min \left(\frac{\mathrm{Pr}-0}{0.3-0}, \frac{0.7-\mathrm{Pr}}{0.7-0.3}\right)\right) \\
& \mu_{\text {quite-likely }}(\mathrm{Pr})=\max \left(0, \min \left(\frac{\mathrm{Pr}-0.3}{0.7-0.3}, \frac{1-\mathrm{Pr}}{1-0.7}\right)\right) \\
& \mu_{\text {most-likely }}(\mathrm{Pr})=\max \left(0, \min \left(1, \frac{\mathrm{Pr}-0.7}{1-0.7}\right)\right)
\end{aligned}
$$

